\title{
RETRACTED ARTICLE: RAPID SCREENING FOR FRAILTY AND SARCOPENIA IN DAILY CLINICAL PRACTICE
}

\author{
B. FOUGÈRE ${ }^{1,2,3}$, J.E. MORLEY ${ }^{3}$
}

\begin{abstract}
1. Division of Geriatric Medicine, Tours University Hospital, Tours, France; 2. Inserm UMR1027, Université de Toulouse III Paul Sabatier, Toulouse, France; 3. Division of Geriatric Medicine, Saint Louis University School of Medicine, St. Louis, Missouri, USA. Corresponding author: Bertrand Fougère, Tours University Hospital - Division of Geriatric medicine, Bretonneau Hospital - Building B1A Level 4, 2, boulevard Tonnellé - 37044 Tours cedex 9, France, e-mail address: b.fougere@gmail.com
\end{abstract}

The Authors have retracted this article because it contains sections that substantially overlap with the following articles (amongst others) $[1,2,3,4,5,6]$. All authors have agreed to this retraction. The online version of this article contains the full text of the retracted article as electronic supplementary material. 